\title{
EMPREENDEDORISMO, INOVAÇÃO E DESENVOLVIMENTO LOCAL: AS MICRO E PEQUENAS EMPRESAS DO INTERIOR NORTE DE PORTUGAL
}

\section{ENTREPRENEURSHIP, INNOVATION AND LOCAL DEVELOPMENT: MICRO AND SMALL ENTERPRISES NORTHERN INTERIOR OF PORTUGAL}

\author{
Maria Ribeiro ${ }^{1}$ \\ António Fernandes ${ }^{2}$ \\ Alda Matos $^{3}$ \\ Paula $\mathrm{Cabo}^{4}$
}

\section{RESUMO}

São muitas as evidências que estabelecem uma relação directa entre o empreendedorismo de uma comunidade e o desenvolvimento económico local. Inúmeros investigadores argumentam que qualquer processo de desenvolvimento económico está associado a inovações geradas por empreendedores. Desta forma, ao empreendedorismo associa-se, na maior parte das vezes, a introdução de inovações na economia, tendo como consequência a evolução e o desenvolvimento da própria sociedade.O objectivo desta comunicação é analisar o fenómeno do empreendedorismo e da inovação nas micro e pequenas empresas de Bragança e Macedo de Cavaleiros bem como o seu contributo para o desenvolvimento local. A recolha de dados foi feita através de entrevistas semi-estruturadas elaboradas com base no questionário de um estudo concluído em Barcelona, pela Universidade da Catalunha, em 2006. Foram recolhidos dados de 65 empresas no período de Novembro de 2010 a Fevereiro de 2011. Os resultados revelam que a maioria dos empreendedores é do género masculino (70,8\%), tem em média 44,7 anos de idade, possui até 9 anos de escolaridade $(65,4 \%)$ e antes da criação da própria empresa, trabalhava por conta de outrem $(83,1 \%)$. Estes empreendedores operam em diversos sectores de actividade, destacando-se, o comércio e a restauração e a construção civil. As empresas estudadas empregam, em média, 5 trabalhadores e 50,8\% atingem um volume de negócios até 100.000 euros, dando um contributo positivo para o desenvolvimento local.

Palavras-chave: Desenvolvimento local, Empreendedorismo, Inovação, Micro-pequenas empresas.

\footnotetext{
ABSTRACT

There are many evidences that establish a direct relationship between the entrepreneurial community and local economic development. Many researchers argue that any economic development process is associated with innovations generated by entrepreneurs. Thus,

${ }^{1}$ Instituto Politécnico de Bragança - Escola Superior Agrária, Universidade de Trás-os-Montes e alto Douro - Centro de Estudos Transdisciplinares para o Desenvolvimento

${ }^{2}$ Instituto Politécnico de Bragança - Escola Superior Agrária, Universidade de Trás-os-Montes e alto Douro - Centro de Estudos Transdisciplinares para o Desenvolvimento

${ }^{3}$ Instituto Politécnico de Bragança - Escola Superior Agrária

${ }^{4}$ Instituto Politécnico de Bragança - Escola Superior Agrária, Instituto Politécnico de Bragança - Centro de Investigação de Montanha
}

Ribeiro, M.; Fernandes, A.; Matos, A.; Cabo, P.; Empreendedorismo, Inovação e Desenvolvimento Local: As Micro e Pequenas Empresas do Interior Norte de Portugal. Revista de Empreendedorismo e Gestão de Micro e Pequenas Empresas V.1, N³, p.34-53, Mai./Jun.2016. Artigo recebido em 18/04/2016. Última versão recebida em 20/05/2016. Aprovado em 25/06/2016. 


\section{Empreendedorismo, Inovação e Desenvolvimento Local: As Micro e Pequenas Empresas do Interior Norte de Portugal.}

entrepreneurship is associated, in most cases, the introduction of innovations in the economy, resulting in the evolution and development of own society.The purpose of this communication is to analyze the phenomenon of entrepreneurship and innovation in micro and small business and Bragança Macedo de Knights and their contribution to local development. Data collection was made through semi-structured interviews prepared based on the questionnaire of a study completed in Barcelona, the University of Catalonia in 2006. 65 companies Data were collected from November 2010 to February 2011. The results show that most entrepreneurs are male (70.8\%), it has on average 44.7 years old, has up to 9 years of education $(65.4 \%)$ and before the company's own creation, working for employed person $(83.1 \%)$. These entrepreneurs operate in various sectors, highlighting the trade and the restoration and construction. The companies studied employ an average of 5 employees and 50.8\% reaching a turnover of up to 100,000 euros, making a positive contribution to local development.

Keywords: Local Development, Entrepreneurship, Innovation, Micro-small businesses.

\section{INTRODUÇÃO}

Qualquer processo de desenvolvimento económico está associado a inovações geradas por empreendedores [1], [2], [3], [4]. Uma atitude empreendedora tem como consequência a criação e inovação de negócios [5], de novos processos, de novos serviços [6] que juntamente com uma gestão de conhecimento pode contribuir para uma estratégia de desenvolvimento que conjuga o crescimento de oportunidades de empregos e o aumento da produtividade [7]. O empreendedorismo dos pequenos negócios é quase, unanimemente, visto como benéfico para a vida económica e social de países e regiões [8]. A contribuição do empreendedorismo ao desenvolvimento económico ocorre, fundamentalmente, pela inovação e pela concorrência no mercado. Mais entradas e ameaças no mercado levam a mais aumento da produtividade e inovação uma vez que a ameaça de serem desalojadas serve como incentivo, para as empresas estabelecidas, para impedir a entrada de concorrentes [8]. O contributo do empreendedorismo é também importante na criação de empregos, no crescimento económico, na melhoria da competitividade, no aproveitamento do potencial dos indivíduos e na exploração dos interesses da sociedade no que diz respeito à protecção do ambiente, produção de serviços de saúde, de serviços de educação e de segurança social [9]. Embora o empreendedorismo por oportunidade tenha um impacto maior sobre o crescimento económico comparativamente ao empreendedorismo por necessidade [10], este último, ocupa um lugar de destaque no que diz respeito à inclusão social e à redução da pobreza, uma vez que pode ser considerado como uma saída profissional que pode garantir um futuro promissor [11] e garantir uma vida digna para os empreendedores [10], [12]. 
Empreendedorismo, Inovação e Desenvolvimento Local: As Micro e Pequenas Empresas do Interior Norte de Portugal.

O empreendedorismo é uma importante fonte de criação de emprego; desempenha um papel fundamental na introdução de inovações na economia e constituise como o mecanismo que leva a economia e a própria sociedade a evoluir e a progredir; é uma opção de carreira para uma parte importante da força de trabalho; e, tem um impacto muito importante no desenvolvimento regional e no crescimento das economias [13]. A principal causa para o crescimento e desenvolvimento é o aumento da eficiência e da competitividade da economia, e no centro desse aumento da eficiência e competitividade está a inovação, e na base da inovação está a iniciativa empresarial, ou seja, o empreendedorismo [14]. Neste contexto, pretendeu-se como esta investigação analisar o fenómeno do empreendedorismo e da inovação nas micro e pequenas empresas, em dois Concelhos do Distrito de Bragança, bem como o seu contributo para o desenvolvimento local.

\section{PARTE EXPERIMENTAL}

Como o próprio nome indica, este ponto é dedicado à apresentação da metodologia usada para levar a cabo esta investigação, designadamente, participantes, material e procedimento. Para isso, faz-se referência à forma como a amostra foi recolhida, ao instrumento de recolha dos dados e ao tratamento estatístico dos mesmos.

\subsection{PARTICIPANTES}

Recolheu-se uma amostra de 65 empreendedores, com idades compreendidas entre 23 e os 67 anos, com uma média de idades de 44,7 anos (DP \pm 11 ). Os negócios, localizados em dois concelhos do Distrito de Bragança, tal como mostra a tabela 1, caracterizam-se por serem micro (80\%) e de pequena (20\%) dimensão.

Os empreendedores são na sua maioria do género masculino (70,7\%) e possuem o ensino obrigatório $(55,4 \%)$. Antes da criação do seu próprio negócio já trabalhavam mas por conta de outrem $(83,1 \%)$, nomeadamente, em empresas privadas $(81,7 \%)$, na empresa dos progenitores (1,5\%) e numa instituição do ensino superior (1,5\%). Apesar de terem criado o seu próprio negócio há uma percentagem relevante que continua a ter uma actividade complementar remunerada (35,4\%). Embora as dificuldades e o contexto económico sejam desfavoráveis ao crescimento e ao desenvolvimento da actividade empresarial, $60 \%$ dos empreendedores gostariam que os seus filhos seguissem o seu exemplo, isto é, criassem a sua própria empresa. 
Empreendedorismo, Inovação e Desenvolvimento Local: As Micro e Pequenas Empresas do Interior Norte de Portugal.

Tabela 1: Caracterização do empreendedor

\begin{tabular}{|c|c|c|}
\hline \multirow[t]{2}{*}{ Grupos } & \multicolumn{2}{|c|}{ Frequências } \\
\hline & Absolutas (n) & Relativas (\%) \\
\hline \multicolumn{3}{|l|}{ Concelho } \\
\hline Bragança & 49 & 75,4 \\
\hline Macedo de Cavaleiros & 16 & 24,6 \\
\hline \multicolumn{3}{|l|}{ Tipo empresa } \\
\hline Micro & 52 & 80 \\
\hline Pequena & 13 & 20 \\
\hline \multicolumn{3}{|l|}{ Género } \\
\hline Feminino & 19 & 29,2 \\
\hline Masculino & 46 & 70,8 \\
\hline \multicolumn{3}{|l|}{ Nível de instrução } \\
\hline $1^{\circ}$ ciclo & 10 & 15,4 \\
\hline $2^{\circ}$ ciclo & 13 & 20 \\
\hline $3^{\circ}$ ciclo & 13 & 20 \\
\hline Secundário & 14 & 21,5 \\
\hline Ensino superior & 15 & 23 \\
\hline \multicolumn{3}{|l|}{ Situação profissional antes da criação do negócio } \\
\hline Trabalhador por conta própria & 5 & 7,7 \\
\hline Trabalhador por conta de outrem & 54 & 83,1 \\
\hline Desempregado & 4 & 6,2 \\
\hline Outra & 2 & 3,1 \\
\hline \multicolumn{3}{|l|}{ Desenvolve actividade complementar remunerada } \\
\hline Sim & 23 & 35,4 \\
\hline Não & 42 & 64,6 \\
\hline \multicolumn{3}{|l|}{ Familiar no mesmo ramo negócio } \\
\hline Sim & 23 & 35,4 \\
\hline Não & 42 & 64,6 \\
\hline \multicolumn{3}{|l|}{$\begin{array}{l}\text { Situação profissional desejada para os } \\
\text { descendentes }\end{array}$} \\
\hline Criar o próprio negócio & 39 & 60 \\
\hline Trabalhador na empresa da família & 15 & 23,1 \\
\hline Trabalhador por conta de outrem & 11 & 16,9 \\
\hline
\end{tabular}

\subsection{MATERIAL}

Para a recolha dos dados foi utilizado como instrumento uma entrevista semiestruturada que resultou da adaptação de questionários sobre o contexto inovador das microempresas e o desenvolvimento local [15], [16]. 
Empreendedorismo, Inovação e Desenvolvimento Local: As Micro e Pequenas Empresas do Interior Norte de Portugal.

\subsection{PROCEDIMENTO}

Foram recolhidos dados de 65 empresas no período de Novembro de 2010 a Fevereiro de 2011. Trata-se, portanto, de um estudo de carácter transversal uma vez que este tipo de estudos envolve a análise de fenómenos que se processam todos numa determinada data e que tenham ocorrido no passado ou no presente [17]. Todos os contactos com os participantes foram feitos, pessoalmente, por um colaborador desta investigação, no seu contexto empresarial. Foi num primeiro contacto que os participantes foram informados sobre a natureza e os objectivos da investigação, se garantiu o anonimato e a confidencialidade dos dados e se procedeu à marcação da entrevista voluntária. O tempo total da entrevista foi, em média, de 60 minutos.

O programa informático utilizado para editar e tratar os dados foi o SPSS 18.0 (Statistical Package for Social Sciences). Recorreu-se à estatística descritiva nomeadamente, ao cálculo de frequências absolutas e relativas sempre que as variáveis eram nominais; e, ao cálculo de medidas de tendência central (média) e medidas de dispersão (desvio-padrão) sempre que as variáveis eram ordinais ou superiores.

\section{RESULTADOS E DISCUSSÃO}

Nesta secção apresentam-se e analisam-se os resultados obtidos na sequência do tratamento dos dados recolhidos através da entrevista semi-estruturada a empreendedores com negócios localizados em dois Concelhos do Distrito de Bragança, designadamente, Bragança e Macedo de Cavaleiros.

\subsection{CARACTERIZAÇÃO DAS EMPRESAS}

Tal como mostra a figura 1, a grande maioria dos empreendedores criaram o seu negócio nas décadas de 80 e 90 do século XX. Precisamente, em Portugal, foi na década de 80 do século passado que se começou a reconhecer a importância do empreendedorismo, fenómeno que estimulava os indivíduos, sobretudo desempregados, a não ficarem à espera de um emprego que poderia não vir, mas a criá-lo, fazendo apelo às competências ganhas ao longo da sua vida profissional ou em outras actividades extra-profissionais Actualmente, este fenómeno está associado à capacidade do indivíduo tomar iniciativas através da transformação de uma ideia num produto/serviço, mediante uma atitude arriscada, inovadora e pró-activa. 
Empreendedorismo, Inovação e Desenvolvimento Local: As Micro e Pequenas Empresas do Interior Norte de Portugal.

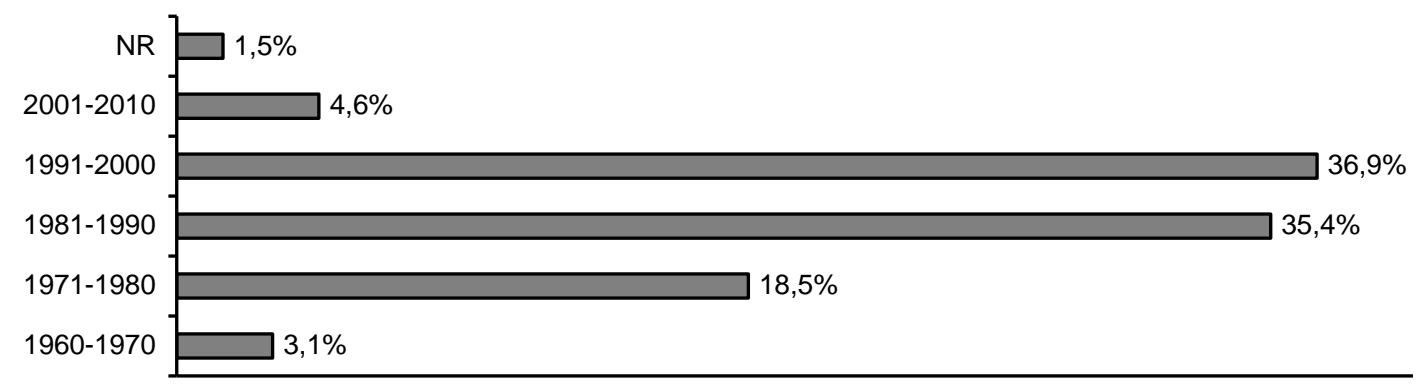

Figura 1: Ano de criação da empresa

Como pode ver-se na tabela 2, o número de sócios do género masculino é superior. Apesar disso, é de notar o aumento do número de sócios registado desde a criação da empresa até à actualidade $(5,6 \%)$ aconteceu a ritmos diferentes quando o género é tido em consideração. De facto, a taxa de crescimento registada pelo género feminino $(13,9 \%)$ é muito superior à do género masculino $(1,5 \%)$.

Tabela 2: Sócios Criadores, Sócios Actuais e Evolução

\begin{tabular}{|l|c|c|c|}
\hline Número Sócios & Homens & Mulheres & Total \\
\hline Criadores & 66 & 36 & 102 \\
Actuais & 67 & 41 & 108 \\
\hline Variação (\%) & $+1,5$ & $+13,9$ & $+5,6$ \\
\hline
\end{tabular}

A motivação económica $(39,4 \%)$ e a realização pessoal $(39,4 \%)$ foram as razões que mais pesaram na decisão de criar a empresa. $O$ desejo de independência é também um dos motivos fortes apontado por 27,3\% dos inquiridos (ver figura 2).

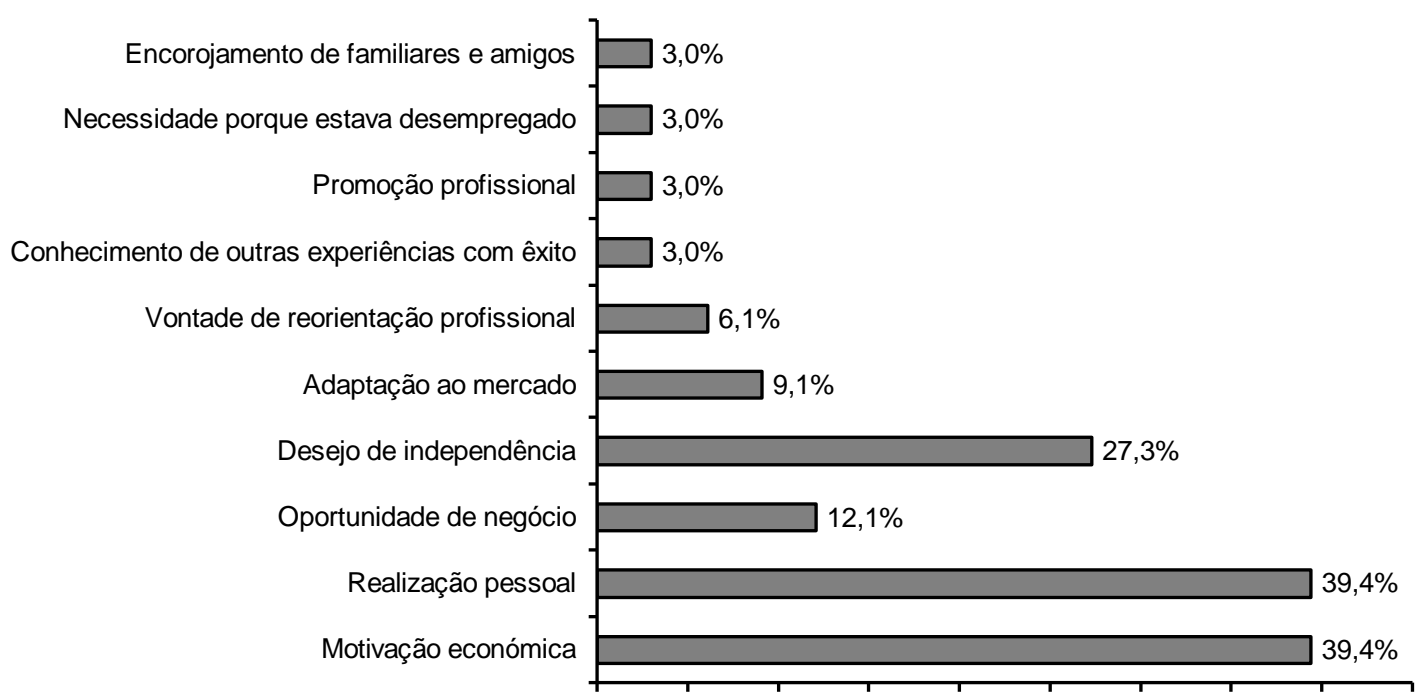

Figura 2: Razões para a criação do negócio 
Empreendedorismo, Inovação e Desenvolvimento Local: As Micro e Pequenas Empresas do Interior Norte de Portugal.

Quando estudados os apoios recebidos aquando da criação e arranque da empresa, verifica-se que muitos dos empresários não receberam qualquer apoio financeiro ou administrativo $(53,8 \%)$, tal como pode ver-se pela figura 3 .

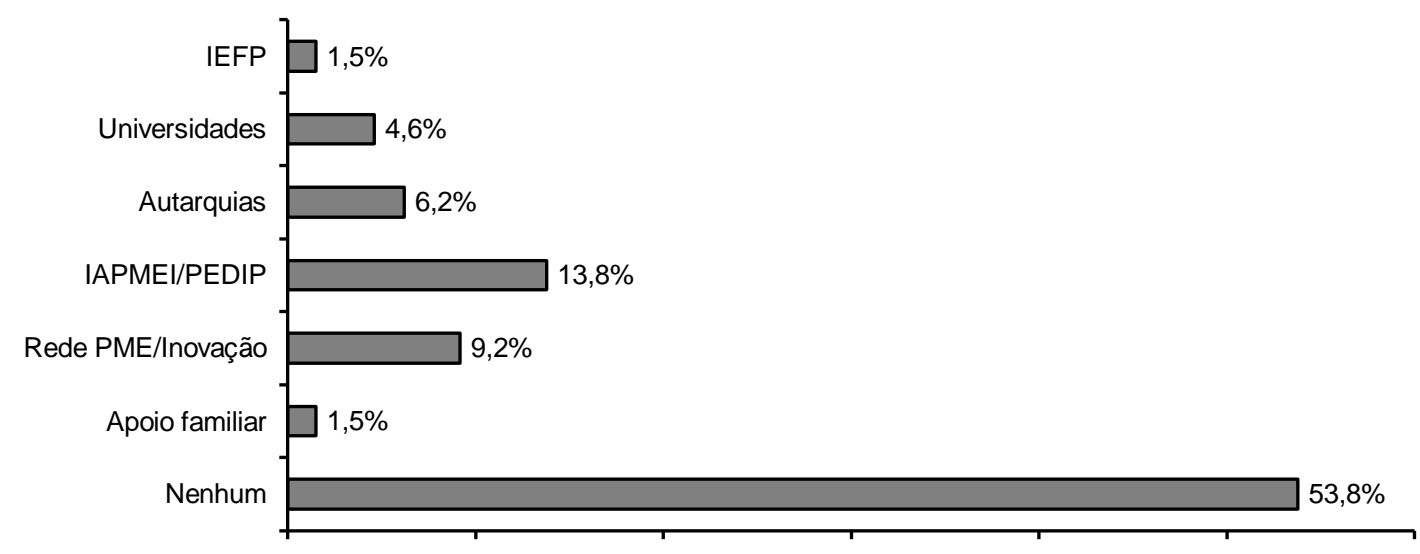

Figura 3: Apoios recebidos para a criação da empresa

Relativamente à actividade desenvolvida pelas empresas verifica-se, pela figura 4, que os sectores mais representativos são, por ordem decrescente de importância, a Restauração e o Comércio (30,8\%), Construção (20\%), Outros Produtos e Serviços (18,5\%), Serviços Pessoais e Actividades Sociais (9,2\%), Produção Industrial (9,2\%), Transportes e Comunicações $(6,2 \%)$ e, por fim, Serviços financeiros, Imobiliários e Empresas (4,6\%).

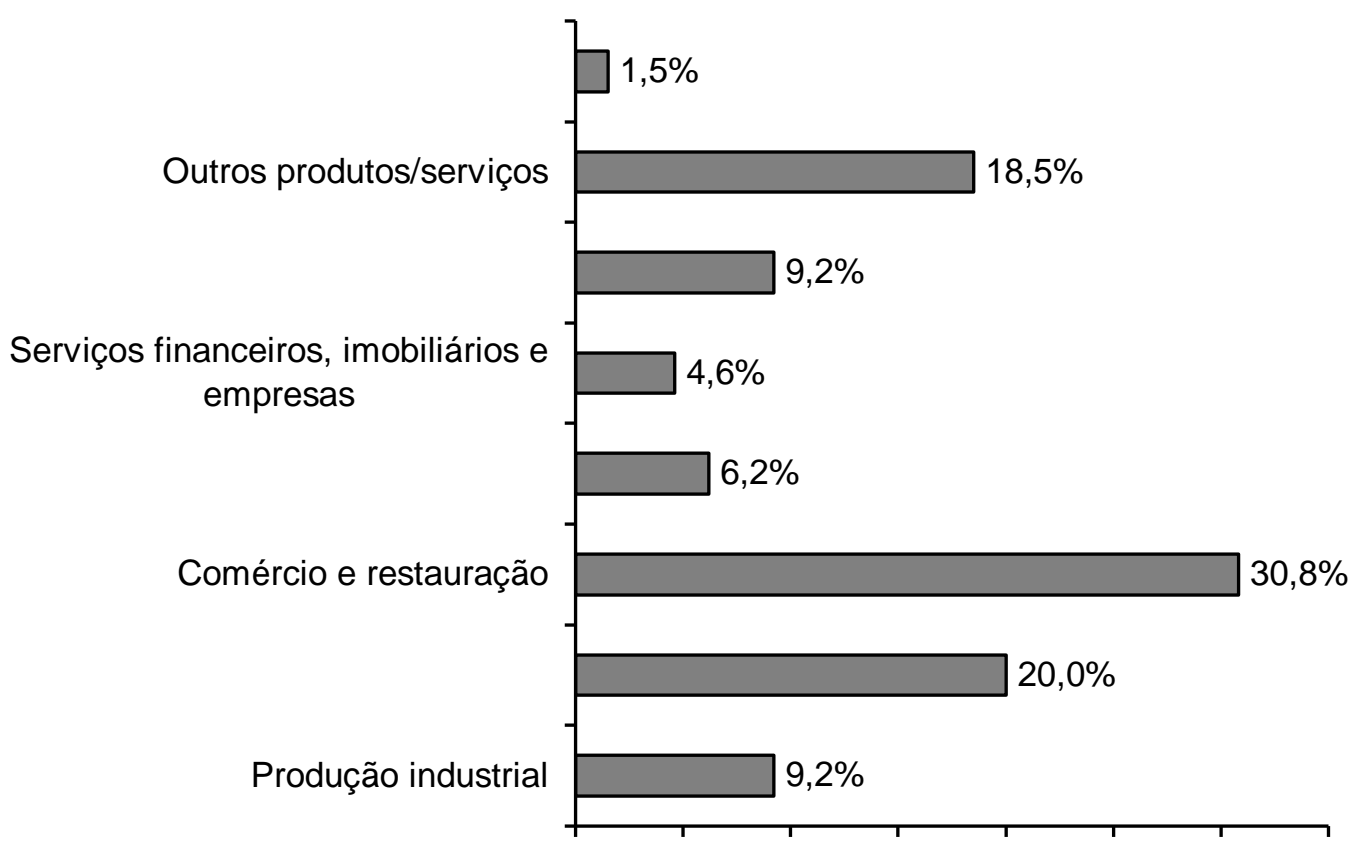

Figura 4: Sector de actividade da empresa 
Empreendedorismo, Inovação e Desenvolvimento Local: As Micro e Pequenas Empresas do Interior Norte de Portugal.

\subsection{ORGANIZAÇÃO DA EMPRESA}

As empresas que fazem parte desta amostra consideram, na sua maioria, estar organizadas por produtos/serviços $(81,5 \%)$, projectos $(64,6 \%)$ e processos $(53,8 \%)$, como pode ver-se na figura 5 .

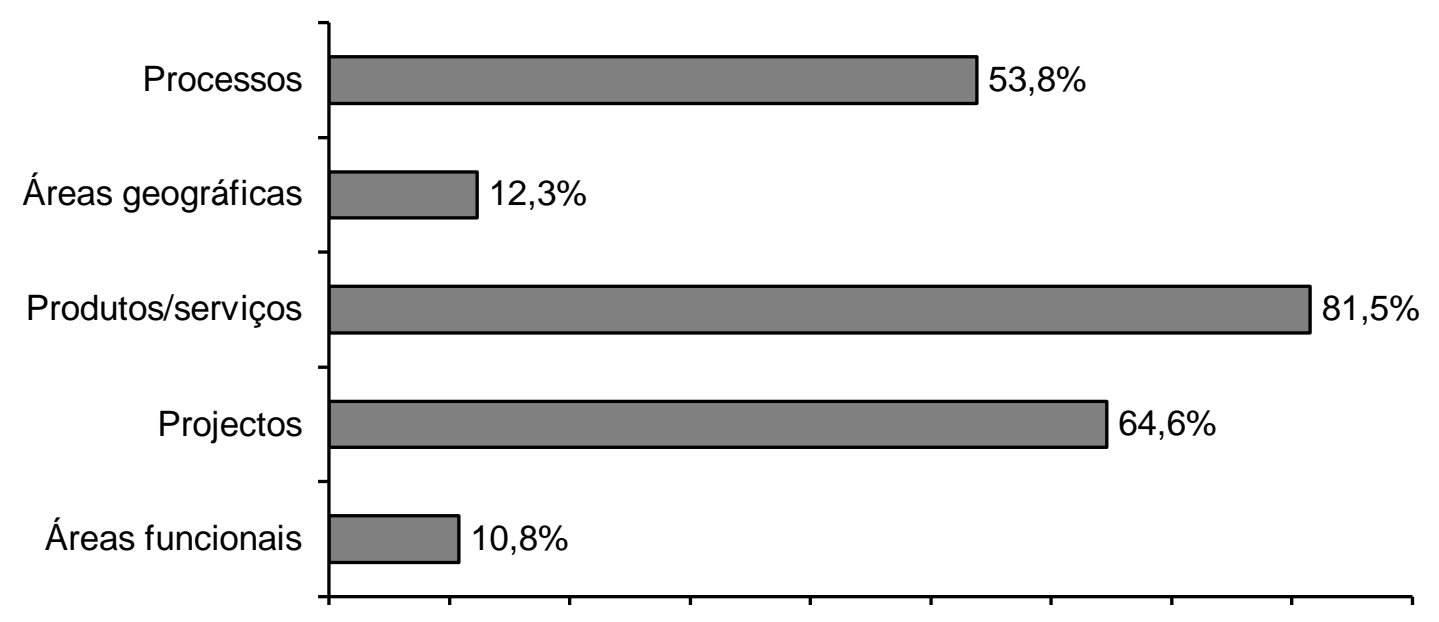

Figura 5: Organização da empresa

A figura 6 revela que, para responder às necessidades do mercado e se adaptarem rapidamente à mudança, as empresas têm equipas de trabalho flexíveis $(35,4 \%)$, privilegiam o trabalho por objectivos/resultados $(26,2 \%)$ e adaptam facilmente as tecnologias em função da procura do mercado $(24,6 \%)$.

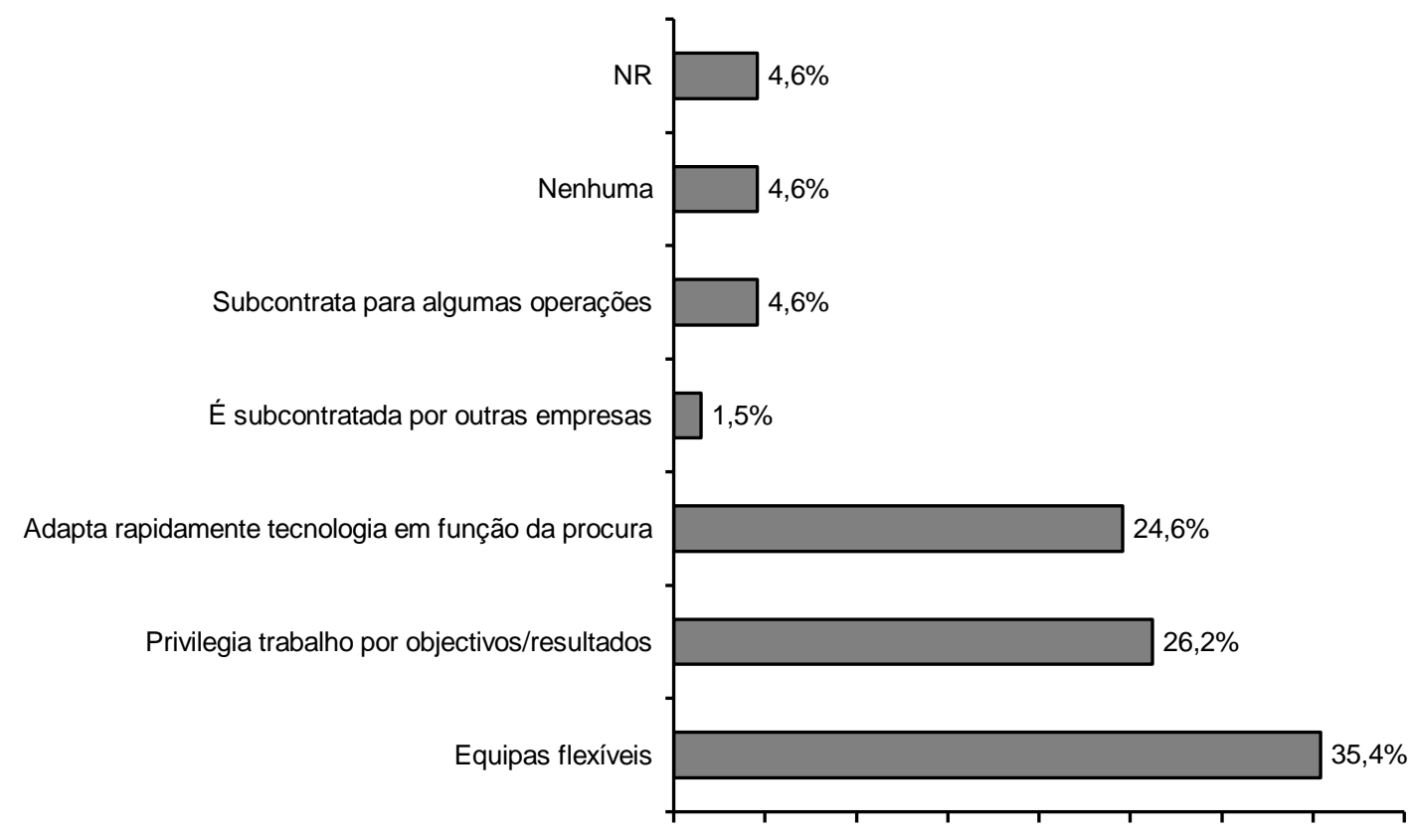

Figura 6: Características organizativas da empresa 


\section{Empreendedorismo, Inovação e Desenvolvimento Local: As Micro e}

Pequenas Empresas do Interior Norte de Portugal.

Para manterem um bom relacionamento com os seus clientes de forma a fidelizá-los, a abordagem seguida pelos empreendedores privilegia a segmentação por clientes $(67,7 \%)$, o desenvolvimento de relacionamentos com os clientes de forma individualizada $(64,6 \%)$ e a elaboração de estudos de mercado (41,5\%) para acompanhar melhor as necessidades e os gostos dos seus clientes (ver figura 7).

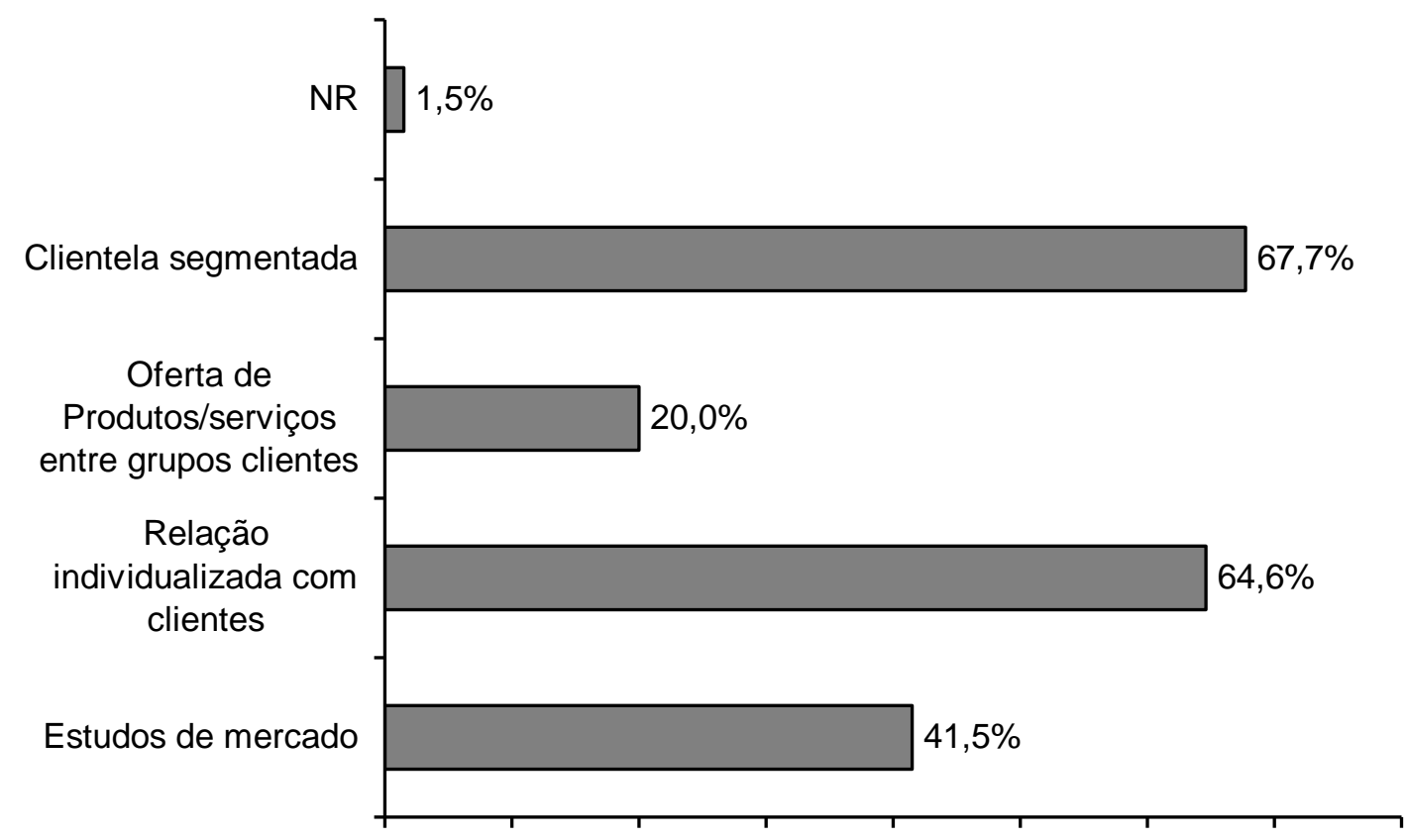

Figura 7: Estratégias de abordagem ao cliente

Tendo em conta a utilização das Tecnologias de Informação e Comunicação (TIC`s) pelas empresas, verifica-se os sistemas informáticos mais utilizados pelas empresas estão relacionados com a contabilidade e facturação (52,5\%), como pode verse na figura 8 . 
Empreendedorismo, Inovação e Desenvolvimento Local: As Micro e Pequenas Empresas do Interior Norte de Portugal.

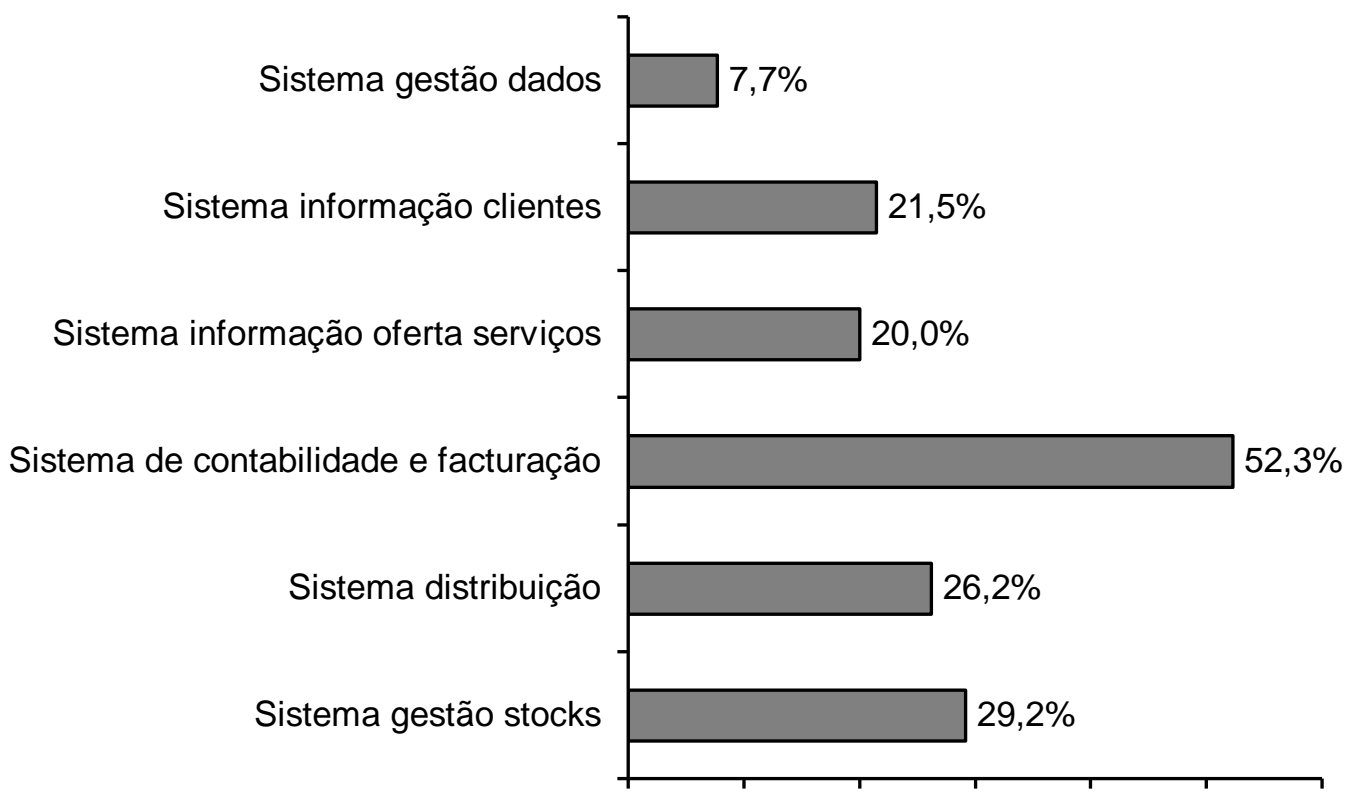

Figura 8: Tecnologias de Informação e Comunicação utilizadas pela empresa

Tal como mostra a figura 9, os maiores benefícios apontados pelas empresas face à sua localização prendem-se com a proximidade dos fornecedores e clientes o que permite poupança nos custos de distribuição dos produtos/serviços, um atendimento mais personalizado, eficiente e eficaz aos clientes e grande disponibilidade por parte dos fornecedores.

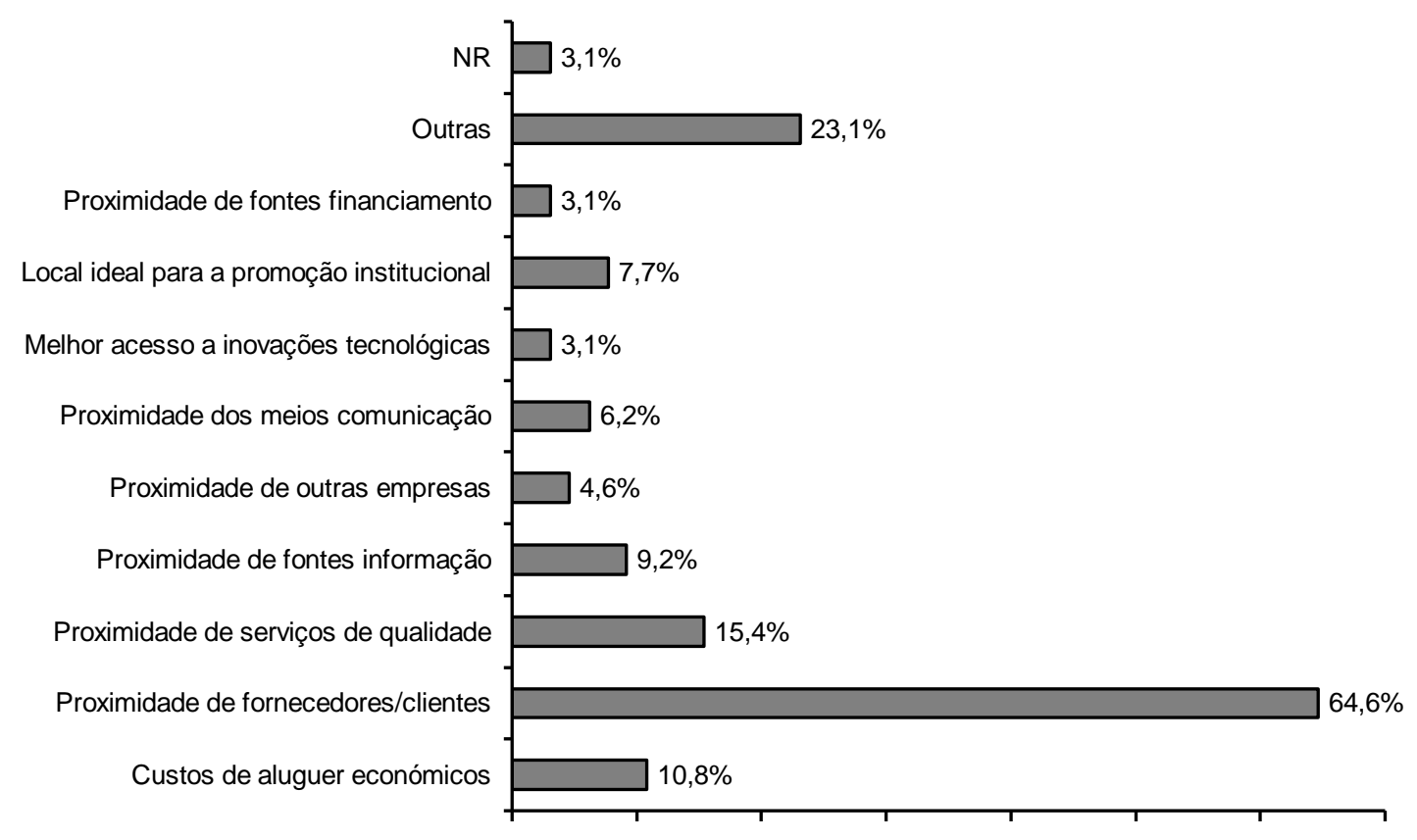

Figura 9: Vantagens da localização da empresa 
Empreendedorismo, Inovação e Desenvolvimento Local: As Micro e Pequenas Empresas do Interior Norte de Portugal.

\subsection{INOVAÇÕES INTRODUZIDAS}

A inovação tornou-se um factor chave no processo de competitividade económica, podendo considerar-se, no âmbito do conceito de sistemas de inovação, duas vertentes complementares, designadamente, institucional e tecnológica [14].

Do total de empresas, 66,2\% introduziram pelo menos uma inovação e, tal como se pode ver pela tabela 3 .

Tabela 3 - Inovações em TIC

\begin{tabular}{|c|c|c|}
\hline \multirow[t]{2}{*}{ Grupos } & \multicolumn{2}{|c|}{ Frequências } \\
\hline & Absoluta (n) & Relativa (\%) \\
\hline \multicolumn{3}{|l|}{ Cooperação na introdução inovações } \\
\hline Não cooperei com ninguém & 22 & 33,8 \\
\hline Centros inovação não universitários & 2 & 3,1 \\
\hline Distribuidores & 15 & 23,1 \\
\hline Fornecedores de tecnologias & 17 & 26,1 \\
\hline Outros fornecedores & 14 & 21,5 \\
\hline Empresas concorrentes & 2 & 3,1 \\
\hline Programa Rede PME/inovação & 7 & 10,8 \\
\hline \multicolumn{3}{|l|}{ Inovações TIC introduzidas } \\
\hline Processos & 11 & 16,9 \\
\hline Produtos/serviços & 28 & 43,1 \\
\hline Organizativo & 29 & 44,6 \\
\hline Nenhum & 20 & 30,8 \\
\hline \multicolumn{3}{|l|}{ Resultados das inovações introduzidas } \\
\hline Nenhum & 1 & 1,5 \\
\hline Gestão logística mais ágil & 14 & 21,5 \\
\hline Oferta de produtos/serviços mais ampla & 14 & 21,5 \\
\hline Processo produtivo mais flexível & 9 & 13,8 \\
\hline Resposta mais rápida ao mercado procura & 17 & 26,2 \\
\hline Nova estrutura organizativa & 17 & 26,2 \\
\hline Gestão interna automatizada & 13 & 20,0 \\
\hline Outros benefícios & 10 & 29,2 \\
\hline \multicolumn{3}{|l|}{ Patentes ideias } \\
\hline Sim & 9 & 13,8 \\
\hline Não & 56 & 86,2 \\
\hline \multicolumn{3}{|l|}{ Origem das Inovações } \\
\hline Não se aplica & 12 & 18,5 \\
\hline O empreendedor & 1 & 1,5 \\
\hline Os trabalhadores & 20 & 30,8 \\
\hline Empresas especializadas & 24 & 36,9 \\
\hline Departamento de design empresa & 9 & 13,8 \\
\hline Ensino superior & 15 & 23,0 \\
\hline
\end{tabular}


Empreendedorismo, Inovação e Desenvolvimento Local: As Micro e Pequenas Empresas do Interior Norte de Portugal.

\begin{tabular}{|l|c|c|}
\hline Importância dos investimentos em I\&D & 12 & 18,5 \\
$<40 \%$ & 14 & 21,5 \\
$40-70 \%$ & 1 & 1,5 \\
$71-90 \%$ & 3 & 4,6 \\
$\approx 100 \%$ & 35 & 53,9 \\
NR & 35 \\
\hline
\end{tabular}

As inovações foram introduzidas cooperando com fornecedores $(47,6 \%)$, por empresas especializadas contratadas para o efeito $(36,9 \%)$ e por trabalhadores da própria empresa $(30,8 \%)$. Tiveram impacto sobretudo na rapidez de resposta ao mercado da procura e ao nível organizativo. Apenas 13,8\% das empresas patentearam essas inovações.

Para cerca de $40 \%$ das empresas, o peso dos investimentos em actividades de I\&D representa até $70 \%$ do total de investimentos efectuados. Contudo, a maioria não fez qualquer investimento em actividades de I\&D $(53,9 \%)$.

\subsection{MERCADO E COMPETITIVIDADE}

O mercado consiste no grupo de clientes ou potenciais clientes que têm a possibilidade ou a vontade de comprar determinados produtos ou serviços, para satisfazer as suas necessidades ou desejos [14].

Relativamente a esta matéria, os resultados mostram que é reduzida a proporção de empreendedores que operam em mercados internacionais. De facto, apenas $12,3 \%$ dos respondentes operam em simultâneo nos mercados nacionais e internacionais. As empresas estão presentes, essencialmente, no mercado Espanhol no qual actuam mais de $75 \%$ das empresas (ver figura 10). 
Empreendedorismo, Inovação e Desenvolvimento Local: As Micro e Pequenas Empresas do Interior Norte de Portugal.
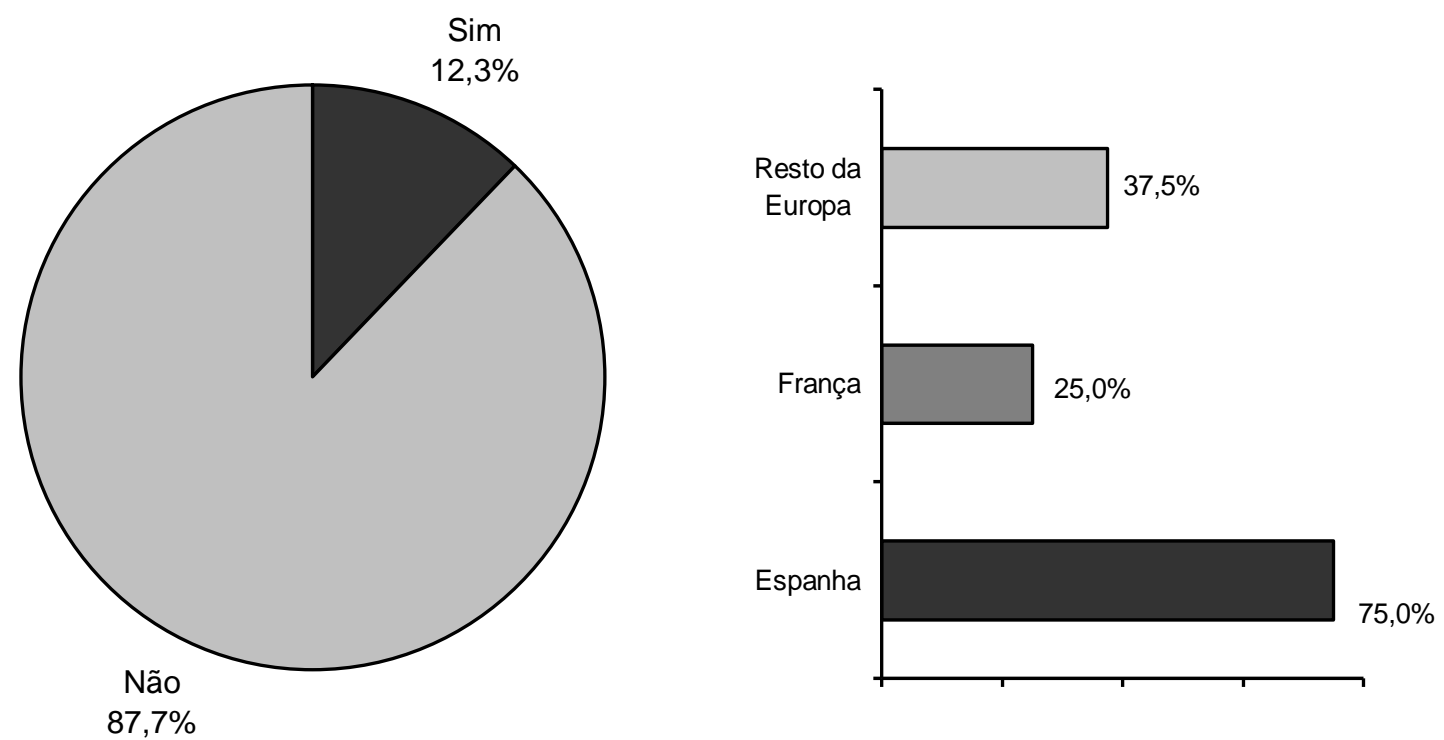

Figura 10: Mercados Internacionais $(n=8)$

A análise de competitividade olha para um conjunto de empresas ou outras instituições/organizações (num dado sector) que disponibilizam determinados produtos ou serviços que são similares ou substitutos, próximos entre si [14].

A grande maioria dos empreendedores considera enfrentar uma pressão competitiva forte. De facto, mais de $50 \%$ dos respondentes considera que a pressão competitiva é alta $(50,8 \%)$ e $20 \%$ considera ser muito alta. Contudo, é expressiva a percentagem de respondentes que considera ter uma pressão competitiva fraca $(27,7 \%)$ (ver figura 11). 
Empreendedorismo, Inovação e Desenvolvimento Local: As Micro e Pequenas Empresas do Interior Norte de Portugal.

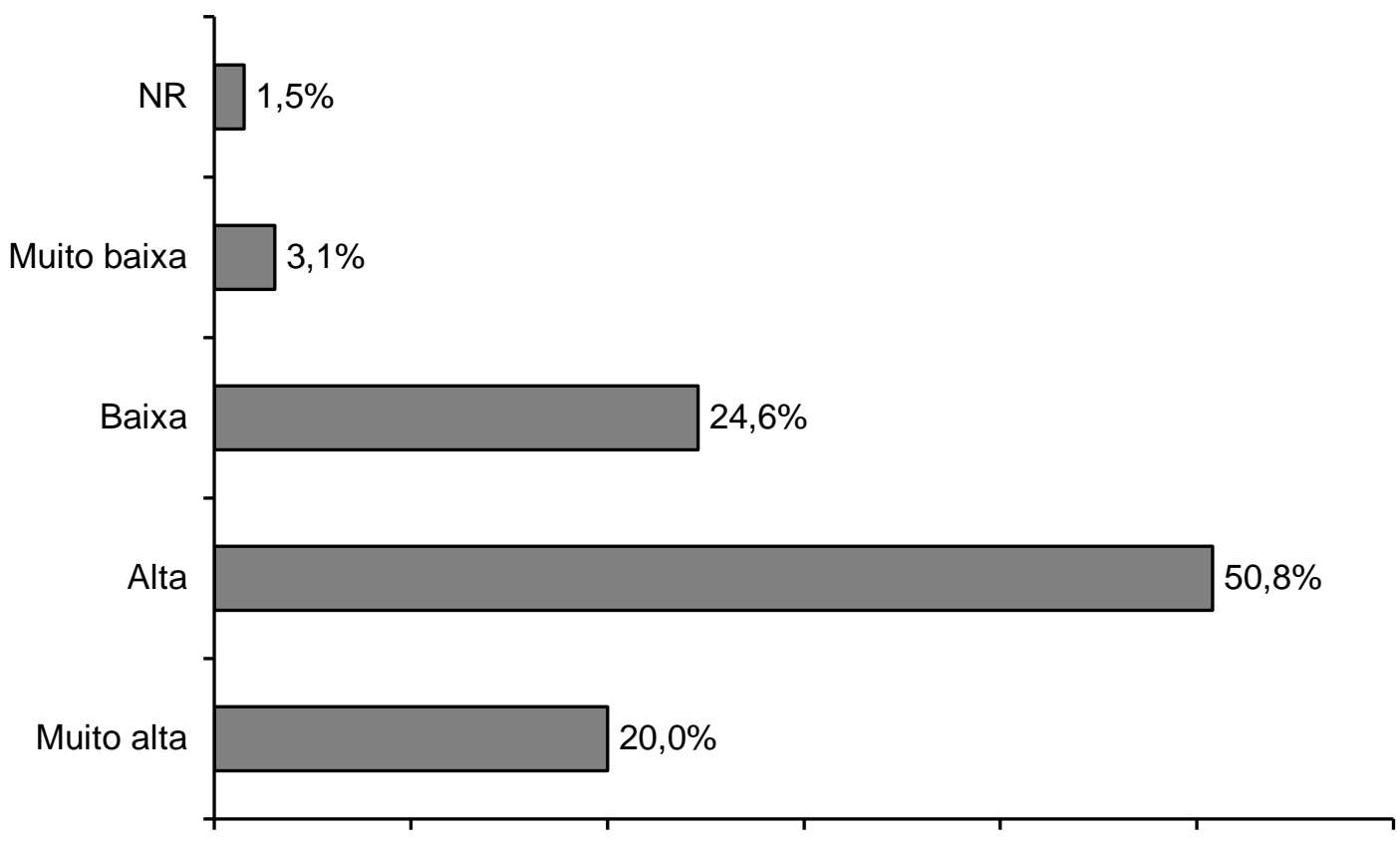

Figura 11: Percepção da pressão competitiva

As empresas estudadas empregam, em média, 5 trabalhadores e 50,8\% atingem um volume de negócios até 100.000 euros dando um contributo positivo para o desenvolvimento socioeconómico local (ver tabela 4).

Tabela 4: Volume negócios, evolução facturação e número de trabalhadores, previsão lucros

\begin{tabular}{|l|c|c|}
\hline Grupos & \multicolumn{2}{|c|}{ Frequências } \\
\cline { 2 - 3 } & Absoluta (n) & Relativa (\%) \\
\hline Volume de negócios $(€)$ & 21 & \\
$<30000$ & 12 & 32,3 \\
$30000-100000$ & 6 & 18,5 \\
$100001-250000$ & 20 & 9,2 \\
$>250000$ & 6 & 30,8 \\
NR & & 9,2 \\
\hline Evolução do número de trabalhadores & 9 & \\
Diminuiu & 52 & 13,8 \\
Manteve-se & 3 & 80,0 \\
Aumentou & 1 & 4,6 \\
NR & & 1,5 \\
\hline Evolução da facturação & 11 & 16,9 \\
Diminuiu & 37 & 56,9 \\
Manteve-se & 15 & 23,1 \\
Aumentou & 2 & 3,1 \\
NR & & \\
\hline Previsão de lucros no presente ano económico & 61 & 93,8 \\
Sim & 4 & 6,2 \\
Não & & \\
\hline
\end{tabular}


Apesar da pressão competitiva, $84 \%$ das empresas manteve (80\%) ou aumentou $(4,6 \%)$ o número de trabalhadores relativamente ao ano anterior. $\mathrm{O}$ mesmo se verificou em relação ao volume de facturação que se manteve ou aumentou para $80 \%$ das empresas. Mais de $90 \%$ das empresas prevê chegar ao fim do ano económico e obter um resultado positivo.

Uma demonstração de como os empreendedores pretendem manter a sua vantagem competitiva no negócio foi o facto de grande percentagem das empresas considerarem que prestam serviços ou oferecem produtos de qualidade $(67,7 \%)$. De facto, a qualidade, como pode ver-se na figura 12, emerge como o factor crítico de sucesso capaz de suportar a estratégia competitiva das empresas estudas.

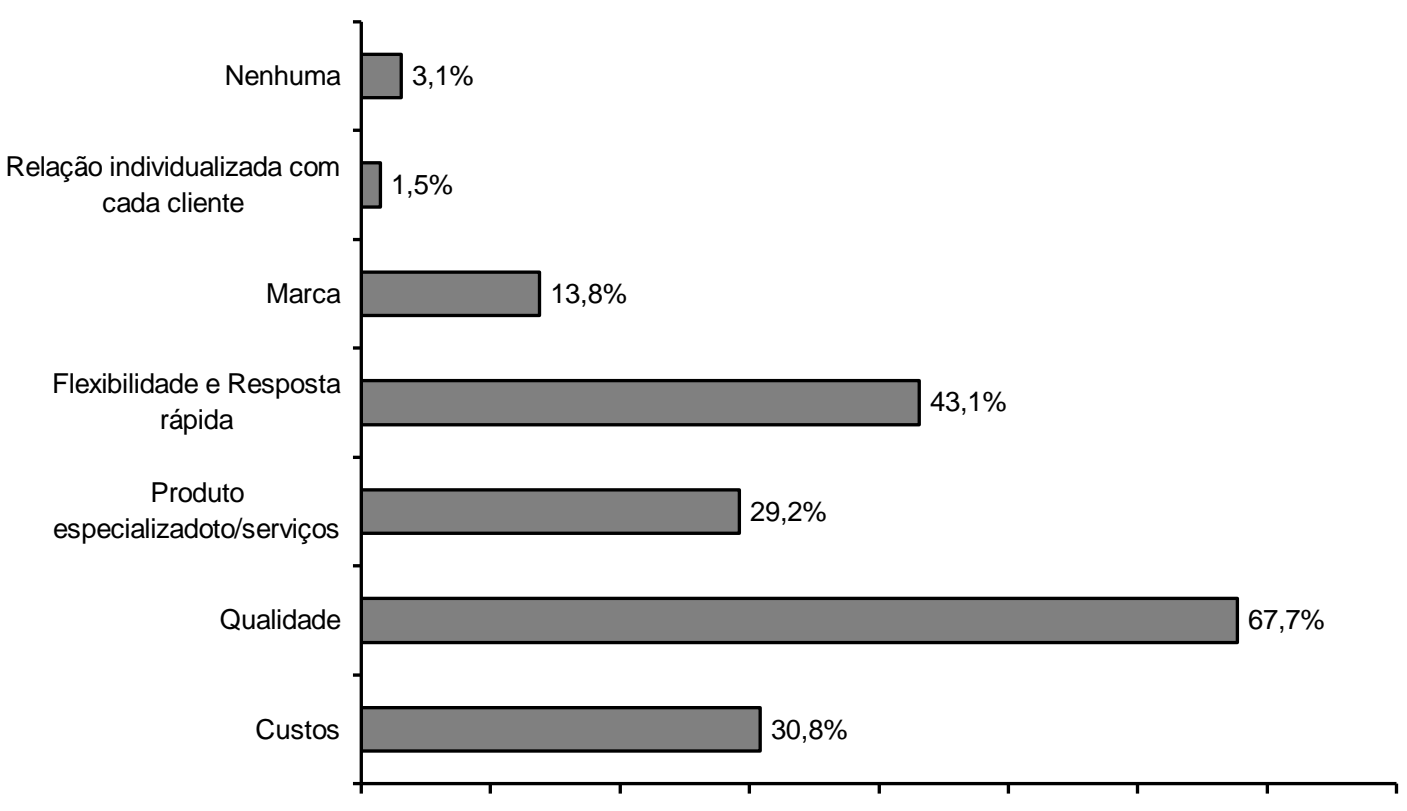

Figura 12: Estratégias predominantes na empresa

A Marca é uma promessa sobre as características e qualidade do produto e sobre a sua manutenção ao longo do tempo [18]. Apesar das vantagens de se investir numa marca, designadamente, a fidelização dos clientes conseguida através da confiança que a marca transmite [18], na opinião destes empresários, a importância da Marca não tem grande expressão $(13,8 \%)$ o que, de alguma forma, parece contradizer a estratégia de fornecimento de produtos/serviços de qualidade 
Empreendedorismo, Inovação e Desenvolvimento Local: As Micro e Pequenas Empresas do Interior Norte de Portugal.

\subsection{CRESCIMENTO DA EMPRESA}

Considerando as estratégias de crescimento, 13,8\% dos empresários querem manter a sua posição actual no mercado. Contudo, a esmagadora maioria pretende crescer adoptando estratégias tais como o desenvolvimento de novos produtos e colocando-os nos mercados onde já opera $(64,6 \%)$ ou conquistar novos mercados com os produtos actuais $(38,5 \%)$ (ver figura 13$)$.

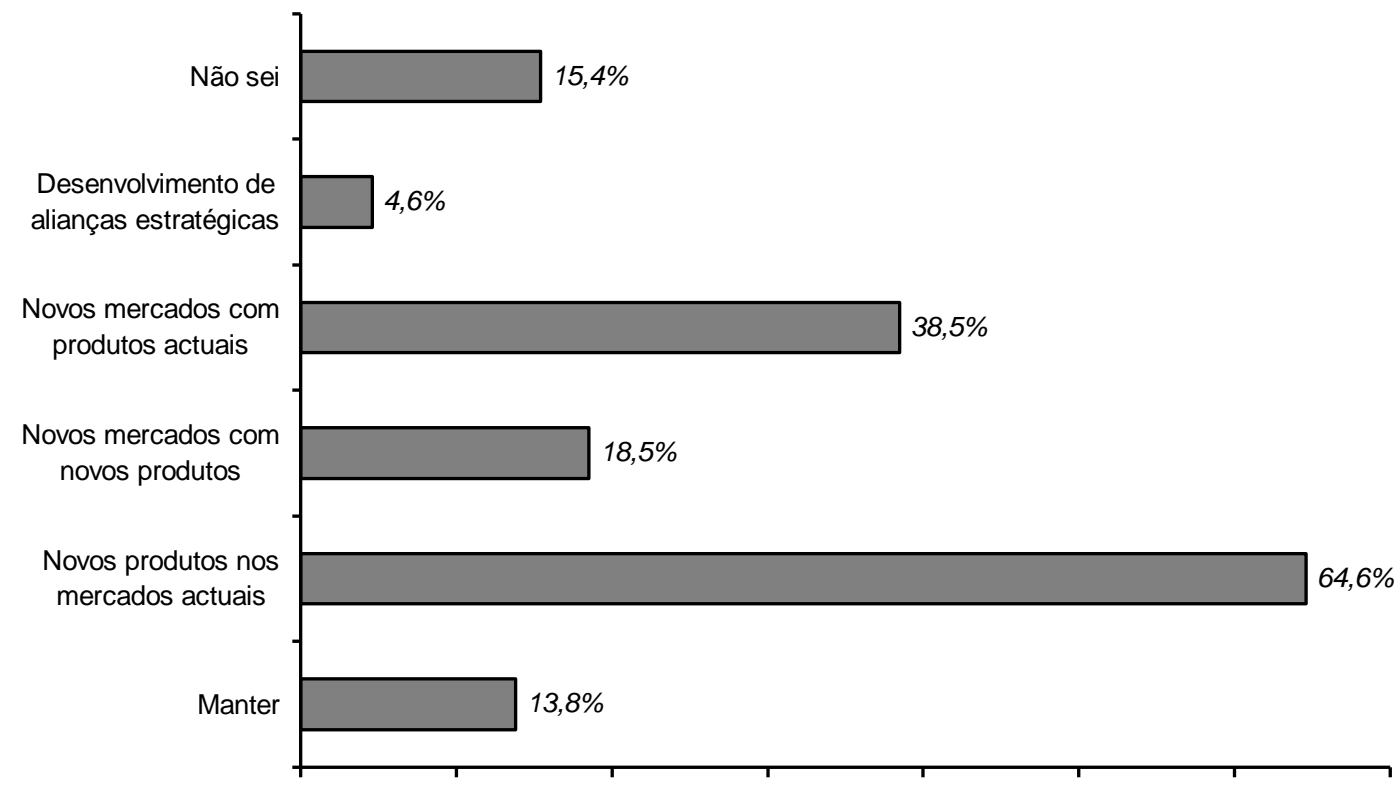

Figura 13: Estratégias de crescimento

A flexibilidade é vista por $80 \%$ dos empreendedores, como uma importante característica para impulsionar o crescimento da empresa uma vez que pretendem desenvolver novos produtos e entrar em novos mercados com os produtos actuais. Mais uma vez, para financiar esse crescimento, a maioria dos empreendedores pretende usar capitais próprios (ver figura 14). 
Empreendedorismo, Inovação e Desenvolvimento Local: As Micro e Pequenas Empresas do Interior Norte de Portugal.
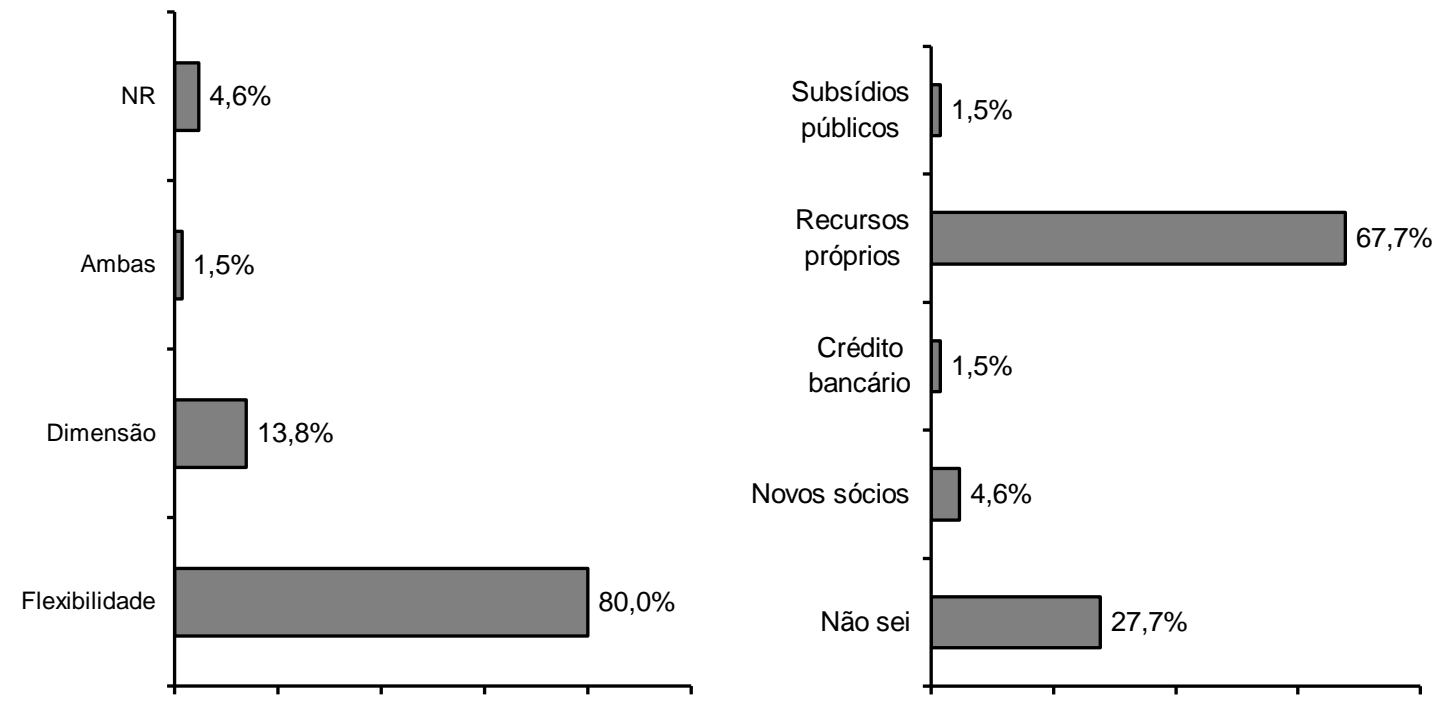

Figura 14:Formas de impulsionar e financiar o crescimento

\subsection{COMÉRCIO ELECTRÓNICO}

O ambiente da Internet tem sido uma importante ferramenta na busca de informações relevantes para a gestão das organizações, na modificação dos processos de negócios e até mesmo na criação de novos modelos de negócios [19]. A expedição dos produtos através da Internet é uma forma de venda de acesso fácil, já que os circuitos curtos de comercialização/venda directa melhoraram os preços na origem, aumentando as receitas das empresas.

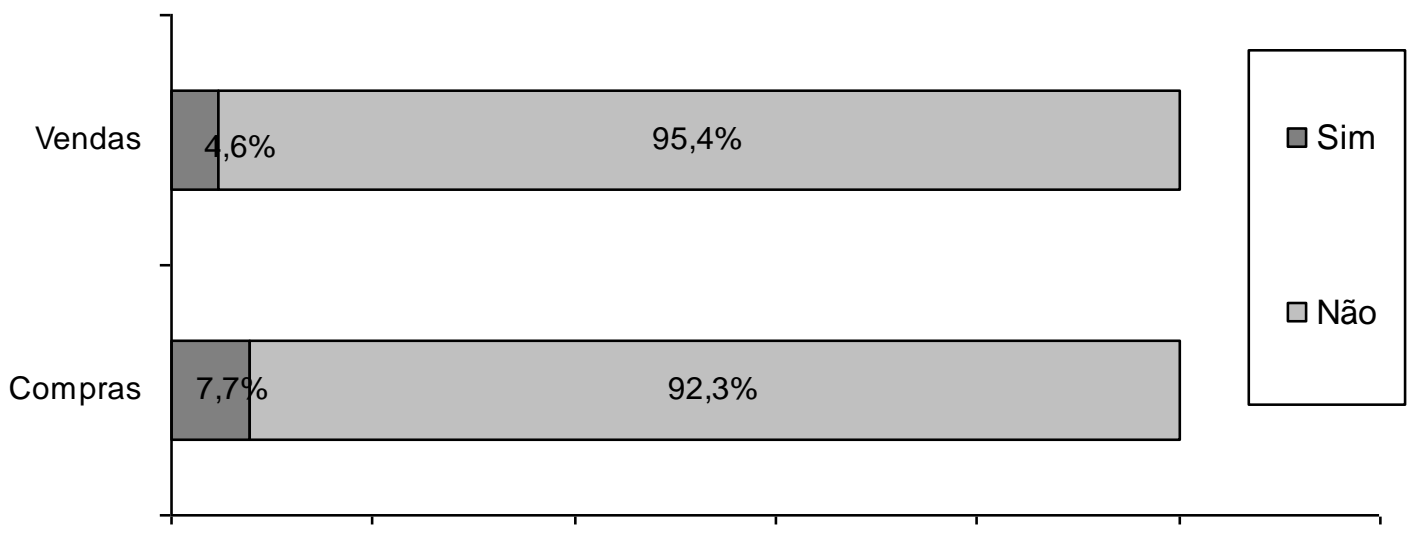

Figura 15: Compras e vendas feitas pela internet

Apesar de quase todas as empresas terem internet $(73,8 \%)$ e uma percentagem significativa possuir uma página Web $(26,2 \%)$, os investimentos em publicidade na 
Empreendedorismo, Inovação e Desenvolvimento Local: As Micro e Pequenas Empresas do Interior Norte de Portugal.

internet representam em média $17 \%$ do total de investimento em publicidade $(1111,5 €)$.

Por outro lado, as actividades comerciais, quer compras, quer vendas, feitas através destas tecnologias são feitas por uma minoria, não atingindo sequer os 10\% (ver figura 15). Contudo, as compras são efectuadas por um maior número de empresas comparativamente às vendas. Os mesmos resultados foram obtidos num estudo que teve como objectivo explorar o fenómeno do empreendedorismo e inovação no seio das PME`s em Portugal junto de 30 empresas da Rede PME inovação COTEC Portugal [16].

\subsection{A CRIAÇÃO DE NOVOS NEGÓCIOS}

Quando se questionaram os empresários sobre a possibilidade de, num futuro próximo, criarem outra empresa, apenas $12,3 \%$ respondem afirmativamente e planeiam a sua criação dentro de um período temporal superior a 12 meses.
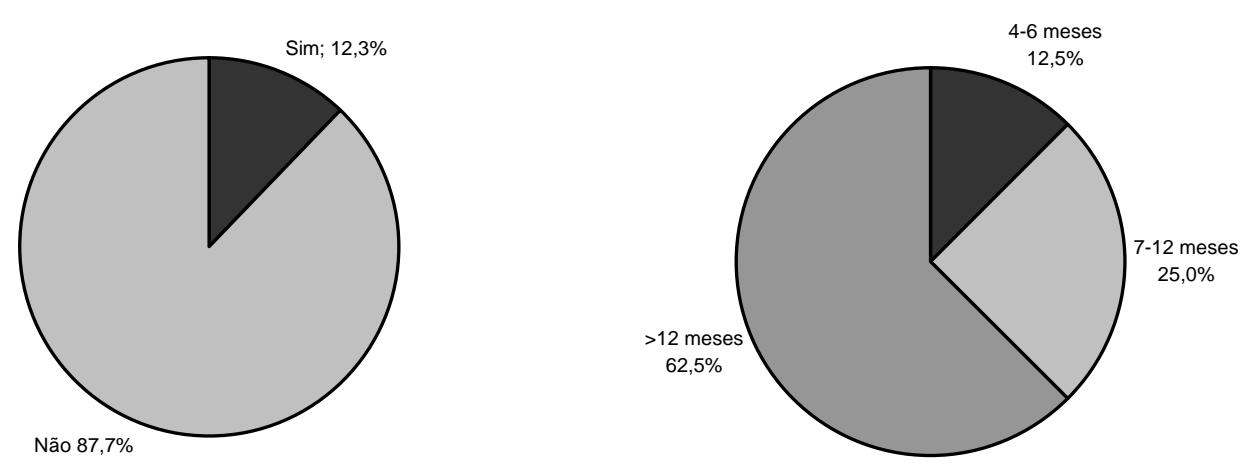

Figura 16: Criação de uma nova empresa e prazo $(n=8)$

Este novo negócio será financiado recorrendo não só a capitais próprios (75\%), mas também a fontes de financiamento tradicionais como o crédito bancário e a fontes de financiamento públicas nacionais e internacionais.

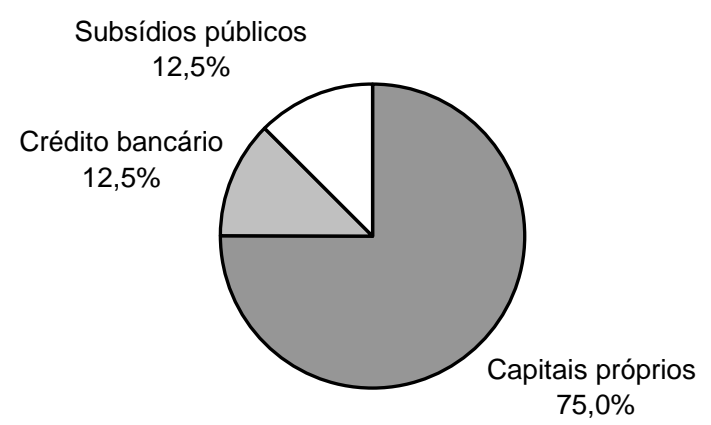

Figura 17 - Fontes de financiamento da nova empresa $(n=8)$ 
Empreendedorismo, Inovação e Desenvolvimento Local: As Micro e Pequenas Empresas do Interior Norte de Portugal.

\section{CONCLUSÕES}

Esta comunicação teve como objectivo analisar o fenómeno do empreendedorismo e da inovação nas micro e pequenas empresas de Bragança e Macedo de Cavaleiros bem como o seu contributo para o desenvolvimento local. Os empreendedores inquiridos têm idades compreendidas entre os 23 e os 67 anos, com uma média de idades de 44,7 anos ( $\mathrm{DP} \pm 11$ ), são na sua maioria do género masculino $(70,7 \%)$ e possuem o ensino obrigatório (55,4\%). A grande maioria dos empreendedores criaram o seu negócio nas décadas de 80 e 90 do século passado e antes da sua criação já trabalhavam por conta de outrem (83,1\%). A motivação económica $(39,4 \%)$ e a realização pessoal $(39,4 \%)$ foram os motivos que mais pesaram na decisão da criação da empresa.

As empresas estudadas empregam, em média, 5 trabalhadores e 50,8\% atingem um volume de negócios até 100.000 euros dando um contributo positivo para o desenvolvimento socioeconómico local. Operam sobretudo no mercado nacional e, apesar da pequena dimensão, $12 \%$ operam também no mercado internacional. Apesar da pressão competitiva, $84 \%$ das empresas manteve $(80 \%)$ ou aumentou $(4,6 \%)$ o número de trabalhadores relativamente ao ano anterior. O mesmo se verificou em relação ao volume de facturação que se manteve ou aumentou para $80 \%$ das empresas. Mais de 90\% das empresas prevê, no fim do ano económico, obter um resultado positivo.

Do total de empresas, 66,2\% introduziram pelo menos uma inovação. Para isso, recorreram principalmente à cooperação com fornecedores $(47,6 \%)$, designadamente, fornecedores de tecnologias e outros fornecedores. Estas inovações tiveram impacto sobretudo na rapidez de resposta ao mercado da procura e ao nível organizativo. Contudo, apenas 13,8\% dos empreendedores afirmaram ter patenteado essas inovações.

Num futuro próximo, $12,3 \%$ dos empreendedores pretendem criar um novo negócio dentro de um período temporal superior a 12 meses. Este novo negócio será financiado recorrendo principalmente a capitais próprios $(75 \%)$ tal como aconteceu na fase de arranque do negócio actual (53,8\%).

\section{AGRADECIMENTOS}

Este trabalho é financiado por: Fundos Europeus Estruturais e de Investimento, na sua componente FEDER, através do Programa Operacional Competitividade e Internacionalização 
Empreendedorismo, Inovação e Desenvolvimento Local: As Micro e Pequenas Empresas do Interior Norte de Portugal.

(COMPETE 2020) [Projeto no 006971 (UID/SOC/04011)]; e por Fundos Nacionais através da FCT -

Fundação para a Ciência e a Tecnologia, no âmbito do projeto UID/SOC/04011/2013.

\section{BIBLIOGRAFIA}

1. Mazzarol, T. et al., Factors influencing small business start-ups: a comparison with previous research, International Journal of Entrepreneurial Behavior \& Research, 5(2): 4863, (1999).

2. Kristiansen, S. \& Indari, N., Entrepreneurial intention among Indonesian and Norwegian students, Journal of Enterprising Culture, 12(1): 55-78, (2004).

3. Acs, Z. et al., What does Entrepreneurship data really show? A comparison of the global entrepreneurship monitor and the Work Bank Group Datasets. World Bank, Policy Research Working paper Series 4467, (2008).

4. Martens, C. \& Freitas, H., Influência do empreendedorismo nas intenções de direccionamento profissional dos estudantes, Estudo \& Debate, Lajeado, 15: 71-95, (2008).

5. Audretsch, D., Innovation, growth and survival, International Journal of Organization, 13: 441-457, (1995).

6. Wong, P. et al., Entrepreneurship, innovation and economic growth: Evidence from GEM data, Small Business Economics, 24 (3): 335-350, (2005).

7. Castillo, P. et al. B., Una Innovación pedagógica para la formación de universitarios emprendedores, Rev. FAE, Curitiba, 11 (2): 113-126, (2008).

8. Barros, A. \& Pereira, C., Empreendedorismo e Crescimento económico: uma análise empírica. RAC, Curitiba, 12(4): 975-993, (2008).

9. Comissão Europeia, Livro Verde: Espírito Empresarial na Europa, Bruxelas: Comissão das Comunidades Europeias, (2003).

10. Degen, R., Empreendedorismo: Uma filosofia para desenvolvimento sustentável e a redução da pobreza, Revista de Ciências da Administração, 10 (21):11-30, (2008).

11. Leite, A. \& Oliveira, F., Empreendedorismo e novas tendências, EDIT VALUE: Consultadoria Empresarial, Universidade do Minho, Braga, Portugal, (2007).

12. Masuda, T., The determinants of latent entrepreneurship in Japan, Small Business Economics, 26: 227-240, (2006).

13. Gaspar, F., The importance of entrepreneurship competitions to spread entrepreneurship spirit and to support startup creation - a survey in Portugal, Actas do $15^{\circ}$ Congresso da APDR, Cidade da Praia, Cabo Verde, (2009).

14. Silva, L. et al., Inovação e criação de novos negócios. Lisboa: Associação de Jovens Agricultores de Portugal, $1^{\text {a }}$ edição, (2009).

15. Montes, G. et al., Entorn innovador, microempreses i desenvolupament local Una anàlisi de les empreses creades amb el suport de Barcelona Activa. Barcelona: Universitat Oberta de Catalunya (UOC), (2006).

16. Cardoso, G. et al., Empreendedorismo e Inovação nas PME's em Portugal: a Rede PME Inovação COTEC, Lisboa: Lisbon Internet and Networks, International Research Programme, (2009).

17. Polit, D. \& Hungler, P., Fundamentos de Pesquisa, $3^{\text {a }}$ Ed., Porto Alegre: Artes Médicas, (1995).

18. Mello, L. \& Marreiros, C., Marketing de Produtos Agrícolas, Lisboa: Associação de Jovens Agricultores de Portugal, $1^{\text {a }}$ edição, (2009).

19. Martens, C. \& Freitas, H., Empreendedorismo e desenvolvimento de micro e pequenas empresas: proposição de um modelo baseado na Internet para estimular a orientação empreendedora, Actas do $3^{\circ}$ Congresso Internacional de Gestão da Tecnologia e Sistemas de Informação (CONTECSI), São Paulo: FEA/USP, p. 245, (2006). 